\title{
The Semantics of Grammatical Elements: A New Solution
}

\section{Giulio Benedetti}

Independent Scholar, Pisa, Italy

\section{Email address:}

benedetti.giulio@tiscali.it

\section{To cite this article:}

Giulio Benedetti. The Semantics of Grammatical Elements: A New Solution. International Journal of Language and Linguistics. Vol. 3, No. 6, 2015, pp. 493-509. doi: 10.11648/j.ij11.20150306.34

\begin{abstract}
This article is an extremely brief introduction to a new theory in the philosophy of language, called Operational Linguistics (OL). OL deals mainly with the semantics of grammatical elements (adpositions/cases, conjunctions, verbs such as to be and to have, modal verbs, numerals, quantity-related, demonstrative and interrogative-relative pronouns/adjectives, main adverbs, negative, interrogative etc.) and terms ("subject", "object", "noun", "verb" etc.), and is based on the fundamental presupposition that their meaning is mainly given by operations within cognitive functions, amongst which those of attention play a key role. Therefore, the meaning of grammatical elements and terms is defined in extra linguistic terms, i. e., based on something other than language. The theory is unitary, in that it accounts for all the grammatical elements and terms on the basis of the same (few) theoretical presuppositions.
\end{abstract}

Keywords: Operational Linguistics, Mental Operations, Attention, Semantics, Grammar, Constructivism

\section{Introduction}

Semantics is a fundamental aspect in the study of language, and a fundamental part of semantics is surely that of grammatical elements, since these are essential for the very existence of language.

This article deals mainly with the semantics of grammatical elements, i. e., adpositions/cases, conjunctions, verbs like to be, to have, modal verbs, numerals, quantityrelated, demonstrative and interrogative-relative pronouns/adjectives, main adverbs, negative, interrogative, etc.. It must be stressed that this subject is dealt with here with a reference to language, not single languages. We assume that the fundamental grammatical elements in the various languages indicate abstract grammatical meanings (such as the genitive, negative, interrogative, for example) that are common to all or almost all languages (in our opinion, the existence of shared meanings is demonstrated by the fact that translation from any language into any other language is almost always substantially possible). In this article, when referring to a particular grammatical meaning (for example, the genitive), we do not intend to refer to the meaning of a particular linguistic element in a language (for example, the morphological marks of the Latin, Greek, Russian etc. genitive, or the English preposition "of", or the French preposition "de"), but to an abstract meaning, which is probably present in all languages. Therefore, the problem of the meaning of grammatical elements is dealt with here from the standpoint of the philosophy of language.

Obviously, both traditional and modern linguistics have tackled the problem of the meaning of grammatical elements. What can be said about the results that have been achieved? In some cases, such as certain prepositions that are strictly related to space, the definitions seem, or may seem, rather satisfactory (see, for example: [1], [2], [3], [4], [5], [6], [7], $[8]$, [9] $)^{1}$. But in many other cases, such as the genitive, negative, verbs such as "to have" and "to be", etc., things seem to be very different. Actually, the results that traditional linguistics achieved in attempting to account for these meanings seem to be unsatisfactory. These results are essentially of the two following kinds:

1) The attempt to account for a meaning leads to tautological or circular definitions: for example, "not" is defined as "negative", "all" is defined as "totality". Clearly, definitions of this kind are totally unsatisfactory.

2) The linguistic element being considered is said to have different meanings according to the context, and the supposed meanings can be many. An emblematic

1 Yet see the in-depth critical revision of this literature by Carstensen ([10], [11], [12], [13]), who stresses the problems of traditional approaches to the semantics of locative expressions. 
example is the genitive, which would indicate various kinds of possession and association, the relationship indicated by the noun being modified, belonging to a group, composition, containing, participation in an action (as an agent or as a patient), origin, cause, purpose, etc.. Other typical examples are verbs such as "to have", "to get" and "to make", which are commonly defined by means of synonyms for each supposed meaning (e. g., to have: to possess, to own, to keep, to get, to obtain, etc.).

Such are essentially the results of traditional linguistics, which can be found in dictionaries and grammar books. Modern linguistics, as we will see, does not seem to have led to a radical change.

This article introduces a new theory that provides a unitary solution to the problem of the meaning of the fundamental grammatical elements. This theory is called Operational Linguistics (OL) (in his former works, the author used the name Operational Semantics, which probably is too restrictive; furthermore, there was a problem of homonymy with a concept in computer science, which has nothing to do with OL).

OL is based on a conception of the human mind that can be considered a moderate form of constructivism. Indeed, although OL explicitly acknowledges the existence of a reality independent from the mind (unlike idealistic philosophy and radical forms of constructivism, e. g., Glasersfeld's constructivism, [14], [15]), OL conceives the mind as having a strong active or constructive character (unlike the more passive conception of the mind as a "reflection" of reality, a conception that is rather widespread in the philosophic tradition). According to OL, languagewhich is a fundamental and distinctive feature of the human mind-is not a mere "labeling" of objects and their reciprocal relationships, but also has a constructive character. In order to account for grammatical meanings, it is therefore necessary to not only consider the objective situation, but also (or, in some cases, above all) what the subject actively does with his/her mind. According to OL in fact, these meanings are mainly made up of sequences of mental operations, amongst which those of attention play a key role. Therefore, this theory accounts for grammatical meanings in extra linguistic terms, i. e., based on something that is outside language, i. e., operations (the name "Operational Linguistics" derives from this) within cognitive functions.

Not only does OL deal with the meaning of grammatical elements, it is a general theory of language and linguistic thought that, as we will see, also offers solutions to other general problems in the philosophy of language (such as the reasons for the difference between human language and animal communication, if language has an innate or acquired origin etc.).

The exposition of this theory (which accounts for the meaning of all the fundamental grammatical elements) requires the space of a book. Therefore, in this article we will consider very few meanings only, in order to give a quick idea of the theory and its novelty and difference from existing theories. Interested readers can find a broader exposition in [16], [17], [18].

In this article, which aims at being as brief as possible, the comparison between OL and other theories has been kept to the minimum.

After these general considerations, we can start to expound the theory. The best way to go about this is not to first expound its principles and then provide concrete examples of their application, but to use a concrete example as the starting point.

\section{The Most Emblematic Case of a Supposed Extensive Polysemy: The Genitive}

The most emblematic case of a supposed extensive polysemy is surely the genitive-which can be expressed by means of a case mark, an adposition ("of", in English), word order (genitive-noun order, in English: e. g., "safety belt"), etc.. Grammar books and dictionaries contain long lists of the following kind (Table 1).

Table 1. The meanings of the genitive.

\begin{tabular}{ll}
\hline possession, various kinds of & $\begin{array}{l}\text { John's eyes, John's car, the } \\
\text { diameter of the sphere } \\
\text { the scent of roses, Raphael's } \\
\text { paintings, 1929 recession }\end{array}$ \\
$\begin{array}{l}\text { association, various kinds of } \\
\text { relationship indicated by the noun } \\
\text { being modified }\end{array}$ & Bob's wife \\
$\begin{array}{l}\text { belonging to a group } \\
\text { composition }\end{array}$ & three of us \\
containing & marble statue, group of men \\
participation in an action, as an & a glass of water \\
$\begin{array}{l}\text { agent } \text { or as } \text { a patient } \\
\text { origin }\end{array}$ & John's arrival, the discovery of \\
cause & America \\
purpose & men of Rome \\
quantity & to die of tuberculosis \\
quality & safety belt \\
denomination & a height of $100 \mathrm{~m}$ \\
plenty or lack & man of honor \\
topic & the city of Rome \\
in respect to & full/devoid of malice \\
fault, accusation and the like & grammar book \\
age & slow of speech \\
\hline
\end{tabular}

Whether explicitly stated or not, these would be the meanings of the genitive. This solution has probably often been considered unsatisfactory, since in the history of linguistics there have been various attempts to account for the meaning of the genitive (in one language or in general) in a monosemic, or at least, in a less polysemic, way. We cannot examine these proposals in depth here. Therefore, we will only mention them, also because they have no analogy with OL's proposal. The Byzantine grammarian Maxime Planude (13th-14th century) was the first to develop a so-called "localistic" theory of (Greek) cases, i. e., a theory (also) based on "spatial" concepts, such as "movement to" and "movement from" (the term "spatial" is used in its most abstract sense, because it can refer to both real spatial 
relationships and grammatical relationships, such as the fact that the genitive is said to indicate the origin of the action in relation to the verb) ([19], [20]). The so-called "Modists" or "speculative" scholastic grammarians (12th-14th century) founded grammar epistemologically on an Aristotelian basis, as a discipline that was abstract and valid for all languages, and described cases in semantic terms only (that is, without using the concept of grammatical relationship): Peter Helia, Simon of Dacia and Martin of Dacia accounted for the Latin cases by using the concepts of "substance" and "action" and the localistic concepts of "origin" (principium) and "end" (terminus) ([19], [21], [22], [23]). In the rationalistic and universalistic approach that predominated in the 17th and 18th centuries, Sanctius and Scioppius defined cases syntactically, i. e., on the basis of the dependence relationships of nouns with the verb, noun, and preposition (the genitive was defined as the case that depends on an expressed or understood substantive) ([21]); Port-Royal grammatical theory ([20]) also considered cases (which it stated to be universal, even if each language expresses them in a specific formal way) as related to syntax, even if it often defined them semantically in a rather traditional way. Structuralism accounted for cases in terms of relationships of opposition to each other: within this approach, Hjelmslev ([20]) defined cases (which he considered abstract and general universal entities, which are expressed in various ways in the various languages) on a semantic basis, by modifying the localistic theory by Maxime Planude; Jakobson ([25]) defined the Russian cases by using a combination of semantic features; de Groot ([26], [27]) and Kuryłowicz ([28], [29]) defined the Latin and Indo-European cases respectively, both in semantic and syntactic terms; Rubio ([30]) defined the Latin cases by using a distinction between the semantic and functional character of the noun (the genitive is said to be semantically a noun, but functionally an adjective); Benveniste ([31]) accounted for the meaning of the Latin genitive in terms of a syntactic transposition of a verb phrase into a noun phrase. Fillmore ([32]) introduced the concept of "deep case", which is a syntactic-semantic relationship of the noun phrase with the verb, which is expressed at the surface level in various ways (morphological cases, adpositions and other ways) in the various languages. The "abstract cases" by Chomsky ([33]) are instead pure syntactic relationships, which any noun phrase is provided with. Anderson ([30], [31], [32]) described cases (which he considered in a universalistic way, like Hjelmslev) semantically on a cognitive basis (by resorting to a combination of spatial concepts). Another attempt with a semantic basis was made by Perret ([33], p. 477), according to whom the genitive is the case of lax determination (as opposed to the accusative, which would be the case of strict determination).

As a general consideration, none of the aforesaid theories has been so successful as to widely substitute the traditional idea that the genitive is very polysemous. Therefore, this solution continues to be substantially accepted in almost all the works where the problem of the meaning of the genitive is somehow involved (see, for example, [38], [39], [40], [41], [42], amongst the various quotable works).

Is it credible that the genitive has all these meanings, i. e., is the solution to the problem of the meaning of the genitive such an extensive polysemy? In order to give an answer to this question, a number of things should be considered.

1) In English, the preposition that expresses the genitive, $i$. e., "of", is the fourth most-used lexeme (Oxford English Dictionary). Moreover, the genitive is also expressed by means of the possessive case or word order.

2) The only well-ascertained polysemy is when a word has one meaning plus very few other meanings, namely the figurative, extended etc. ones, that derive from the first meaning for easily understandable reasons (e. g., the term "nose" means a part of the face, but also snout, muzzle, shrewdness, the opening of a tube etc., a spy). In the case of the genitive, its (supposed) polysemy is very different: there is not a main meaning plus some other meanings that derive from the first for easily understandable reasons, but there would be many different meanings that have nothing to do with each other.

3) The supposed meanings of the genitive are extremely heterogeneous. Why should relationships that are so different from each other be expressed by the same linguistic element? Homonymy definitely does not come into play here.

4) The relationships are so many that one could say that no relationship seems to be excluded. In fact, this seems exactly the case. What relationship does not fall into any of these categories?

5) The supposed meanings of the genitive are substantially the same in many languages. This is a very strong argument against the thesis that the genitive is polysemous. Indeed, in commonly-found polysemy, the polysemy of a given word is generally not the same across the various languages. For example, in English, as mentioned, the word "nose" can also mean a spy, but this does not happen in Italian. If the answer to the problem of the meaning of the genitive were really the polysemy that is supposed, why should this (moreover, such extensive) polysemy be substantially the same for many languages?

In brief, the situation is the following. An extremely important element of language is supposed to have a huge amount of meanings, which would be unrelated to and completely different from each other (unlike the kind of polysemy that is commonly found). The polysemy is extremely extensive (no relationship seems to be excluded) and substantially the same in many languages (while in commonly-found polysemy, the polysemy of a given word is generally different across the various languages).

Well, bearing these considerations in mind, can the right solution to the problem of the meaning of the genitive really lie in this huge polysemy? Our answer is no, by no means. The traditionally proposed solution implies a situation that is really too paradoxical. 
Let us examine the (completely different) solution suggested by OL to the problem of the meaning of the genitive. According to $\mathrm{OL}$, the solution to this problem should not be searched for at the level of the particular relationships between the things that are related by the genitive, i. e., the relationships in Table 1. These are not the meanings of the genitive. These are the cases where the genitive can be used, which is a very different thing. The genitive can be used in all cases where there is a relationship (any relationship) between two things. Therefore, the relationships between things related by the genitive are all the possible relationships (hence, this seeming huge polysemy). Yet the function of the genitive is not to designate all these relationships. Designating such a big variety of relationships by means of the same linguistic element makes no sense. The function of the genitive (i.e., its meaning) is to induce the listener's attention to focus on something, A, by means of the relationship that $\mathrm{A}$ has with something else, $\mathrm{B}$, and to bear in mind the existence of this relationship. In other words, the genitive indicates the attentional focalization of something, A, while bearing in mind that A has been previously focused on together with something else, B.

Examine the examples in Table 1. One can probably sense that the meaning of the genitive is all in this focusing the attention on something while keeping present that this something has some relationship with something else. For example, the phrase "John's car" does not simply and specifically express the relationship of possession. If we want to do this, we say "John has a car". If we say "John's car", we want the addressee to focus his/her attention on a certain car (while keeping present the fact that the car is possessed by John), in order to say something about this car (for example, that it "is red"). The same can be said of the phrases "marble statue", "glass of water", "Bob's wife", etc.. With the genitive we are not simply and specifically designating the relationship of composition, containing, the conjugal relationship, etc., respectively. These things are indicated by the expression as a whole or the context, not by the genitive. The best proof of this is that an expression such as "my friend's picture", if it is isolated, is ambiguous as regards these relationships, because it can indicate a picture possessed by, or painted by, or that shows, a friend of the speaker (moreover, one should note that, in particular contexts, this expression may indicate other kinds of relationships too: for example, amongst pictures that are chosen, indicated, sold, restored etc. by different persons, the expression "my friend's picture" may indicate these relationships). But it is not at all ambiguous that we want to talk about a "picture", while bearing in mind that it is in some way associated with "my friend", that is, we want to talk about something, while bearing in mind that that something is in some way associated with something else. This is the meaning of the genitive. Only and simply this. Therefore, a phrase such as "my friend's picture" does not mean "the picture possessed by my friend" or "the picture painted by my friend" or "the picture that shows my friend". It means "the picture that has some relationship (relationship that is known on the basis of the general knowledge or the context) with my friend". The same can be said of all the phrases with the genitive.

The reason for the existence of the genitive is its huge practical usefulness. Indeed, indicating something, $A$, while bearing in mind the relationship that $A$ has with something else, $B$, is used for at least two very important purposes: a) identifying A amongst the various possible items of the same class ("John's car"); b) speaking about $A$ together with something else we are interested in, such as a quality of it ("marble statue"), its function ("safety belt"), cause ("to die of tuberculosis"), agent or patient, if $A$ is an activity ("John's arrival", "the discovery of America"), etc..

As we can see, OL changes the traditional approach radically, since OL investigates the meaning of the genitive at a completely different level from the other approaches.

a) have sought to account for this meaning by providing a list of the possible relationships between things that are related by the genitive, or looking for something so general as to include all these relationships; or else,

b) have considered the genitive a mere syntactic relationship.

In other words, the meaning has been searched for, so to say, "in the things", i. e., in the objective situations where the genitive is used. OL uses a completely different approach: it mainly investigates the meaning of the genitive at the level of the mental operations performed by the speaker, i. e., the subject.

As a result, OL reduces the hardly believable wide polysemy of the genitive to absolute monosemy, in agreement with the fact that the linguistic element that expresses the genitive is unique (of course, the fact that some languages can express the basic meaning of the genitive in more than one way, as happens in English-possessive case, preposition "of", word order-does not matter: here we are not interested in the possible secondary differences of these forms, but in their common basic meaning).

\section{Operational Linguistics in Brief}

I have introduced my analysis of the genitive before outlining its underlying theory. At this point however, the most general outlines of the theory should be presented.

\subsection{The Origins of $\mathrm{OL}$}

OL derives from Silvio Ceccato's (1914-1997) thought, of which it preserves several theses. Nevertheless, OL is a broad and innovative development of Ceccato's thought and noticeably different from it in part.

Ceccato's thought started developing in the 1950s and reached its full maturity in the 60s and 70s ([43], [44], [45], [46], [47], [48], [49], [50]). Ceccato used various names for his theory. The name Operational Methodology (OM) is the one that has prevailed in his School, the Scuola Operativa Italiana (SOI) [Italian Operational School]. Ceccato was well-known in Italian philosophical circles since the 40s and directed important projects involving the application of his 
theories, namely: a) one of the very few machine translation projects in Europe and the only one in Italy in the first phase of research in this field (funded by the U. S. Air Force, 195966 ; described in [42]); b) the so-called "mechanical reporter" project, i. e., a machine that had to be able to observe and describe a scene made up of seven objects arranged in various ways on a stage (Italian National Research Council, 1958-66; described by [42]). Nevertheless, his thought has not received much attention. This can be due to various reasons, which cannot be examined here. Yet we believe that the work of Ceccato, while requiring an in-depth critical revision, includes many original and valuable ideas and intuitions, which deserve to be taken into consideration again and developed. This is precisely where the author has focused his work ever since the second half of the 90s ([51], [52], [53], [54], [55], [56], [57], [58], [59], [60]).

In this article, there is the problem of distinguishing Ceccato's original theses from those of the author. Therefore, in the text which are Ceccato's main original theses and which are the author's is indicated. When this is not provided, the thought exposed is the author's own, with influences from Ceccato. The above exposed analysis of the genitive is entirely the author's own, as well as the way of exposing the subject, which differs entirely from Ceccato's.

\subsection{The Fundamental Theses of $\mathrm{OL}$}

As mentioned, the fundamental thesis of OL is that grammatical elements designate sequences of mental operations amongst which the ones of attention play a key role (this thesis is Ceccato's own). Therefore, we may say that grammatical elements are "tools to pilot attention" ([61], [62], [63]) and other cognitive functions of the listener.

Ceccato called these sequences of mental operations "mental categories", because they have some analogies with the categories of Kant's philosophy. OL has adopted this name as well ${ }^{2}$. We call the mental operations that make up the mental categories elemental mental operations (EOMC). Therefore, defining the meaning of a linguistic element that designates a mental category means, according to OL, identifying the structure of that mental category, i. e., the sequence of elemental mental operations that make it up. We call this task "analysis of a mental category".

The system of EOMC we propose, which is very different and much more complex than Ceccato's, is the following.

1) Operation of attentional focalization $(\boldsymbol{A F})$ - This operation has the fundamental property of "selecting", or "highlighting" its object with respect to all the rest

\footnotetext{
2 We must point out that the meaning OL gives to the term "category" is completely different from the meaning that cognitive psychology and linguistics give to the same term. Typically, cognitive psychology and linguistics use the term "category" to highlight the fact that, since many objects of the physical world share common features, but are not identical, we create classes (that is, categories) by means of a mental process of abstraction ([64], [65], [66], [67]). On the contrary, OL uses the expression "mental categories" to indicate the meanings of the linguistic elements that do not designate physical (or psychical) things.
}

([68]). Inside AF we can distinguish various suboperations.

a) AF can widely vary in extension (AFext): it may concern an object, or a part of it, or several objects.

b) The focus of attention can move (AFmov) from one object to another, or from a part of the field to which it is applied to another.

c) AF can last for variable, though limited, amounts of time (AFdur [dur = duration]).

d) The extension, movement and duration of attentional focalization can be estimated in quantitative terms (AFext-estim, AFmov-estim and AFdur-estim, respectively).

e) AF can vary in intensity (AFint-var), that is, we can pay more attention to one object instead of another.

2) Presence keeping (PK) - This is the term we will use for the fundamental operation of "bearing in mind" something that has been focused on by attention, $A$, while the attention focuses on something else, $B$. If, for example, we hear the expression "bottle and glass", we keep the meaning "bottle" present when we add the meaning "glass", which we would not do if these two words were isolated, i. e., not related by the conjunction "and".

The operation of presence keeping is surely strictly related to the well-known concept, developed by cognitive psychology, of "working (or active) memory", whether in the classic Baddeley-Hitch model ([69], [70]) or in more recent models, such as Cowan's or Oberauer's ([71], [72]; [73]; [74]), which highlight the tight interaction between working memory and attention.

3) Operation of attentional discarding (AD) - If we say "glass or bottle", we can sense that both objects are focused on by attention and kept present, but when our attention focuses on the bottle, we must exclude, discard the glass. This operation is completely different from simply stopping to focus our attention on an object in order to pass on and focus on another object. In our case, we must bear an object in mind while somehow excluding it. We call this operation "attentional discarding".

4) Operation of representation $(\boldsymbol{R})$ - The operation of representation is the act of thinking about something that is not present at the moment. This is what we do when, for example, hearing a word, we pass on to its meaning, which was previously memorized. Obviously, attention is also involved in the operation of representation (which is proven by the fact that when we imagine something it is difficult to pay attention to something else), but in representation the attention focuses on what this operation produces (that is, attention is not alone, but accompanies the other operation).

5) Operation of comparison (C) - Our mind performs comparisons very frequently. Every time we use typically relative words, which concern properties of an object (like "high/low", "strong/weak", "heavy/light" 
etc.) or express a judgement (like "good/bad", "normal/abnormal" etc.), we make comparisons. Obviously, when we perform this operation, we focus our attention on the objects compared and we bear them in mind. Even though comparison implies operations of attentional focalization and presence keeping, we believe that it has to be considered a separate function.

6) Operations of memory (MO) - Memory surely plays a key role in our mental life: by means of it, we fix and recall memories continuously. Apart from all of this, we think that memory operations are part of the structure of some mental categories ([54], [56]). Therefore, we list memory operations amongst the basic mental operations that make up mental categories.

Almost all of the operations that we consider EOMC have been repeatedly described in cognitive psychology ${ }^{3}$. The new idea we are putting forward is that by means of these operations we can account for the meaning of grammatical elements.

\section{Another Case of Supposed Extensive Polysemy: Preposition "with"/Verbs "to Have" and "to Get"}

The preposition "with" and the verbs "to have" and "to get" (these three meanings are based on the same core of operations, as we will soon see) are other examples of words that are traditionally believed to be polysemous. Indeed, grammar books and dictionaries state that the preposition "with" "indicates several relationships" (or similar expressions), and provide lists that are similar to that in Table 2.

Table 2. The meanings of the preposition "with".

\begin{tabular}{|c|c|}
\hline company or union & John with his wife, cup with handle \\
\hline means or instrument & to write with a pen \\
\hline manner & with ease \\
\hline cause & to shiver with fear \\
\hline quality & man with a moustache \\
\hline time & swallows migrate with the cold season \\
\hline opposition & to fight with the enemy \\
\hline in comparisons & to compare your work with mine \\
\hline relationship & business dealings with Japan \\
\hline concessive meaning & with all his faults, I like him \\
\hline etc. & \\
\hline
\end{tabular}

Things are not very different in modern linguistics. Prepositions are generally said to be polysemous (see, for example: [88], [89], [90], [91], [92], [93], [94]) and, whether explicitly stated or not, these would be the meanings of the preposition "with". Can such a frequently used and essential word have so many different meanings? Is not it much more

3 As regards attention, see for example [68], [75], [76], [77], [78], [79], [80], [81]; as to representation, see [82], [83], [84]; as to memory, see [70], [69], [71], [72], [85], [74], [73]; in general, see [86], [87]. convincing to think that this word has only one, more general meaning (which is why it is so difficult to determine) and as such lends itself to express the many relationships grammar speaks about? This meaning is so general because it does not lie at the level of the aforesaid more particular relationships grammar speaks about, but at a much more abstract level, i. e., the level of operations within cognitive functions that the described situation induces or allows to be performed. According to OL, the preposition "with" means that we focus our attention (AF) on something, $A$, then, keeping it present (PK), our attention is also extended (AFext) to something else, $B$, because $B$ is related to $A$ in such a way that our attention tends to include $A$ and $B$ in a single focalization (for example, we say "bottle with cork" if the cork is in the neck of the bottle; we cannot use this expression if the cork is far from the bottle; this analysis is the author's own).

This analysis clearly explains why in many languages this preposition is used to express two very different relationships i. e., the relationship of company or union between two things and the relationship of means or instrument between an activity and an object. Indeed, whether we say, for example, "cup with handle" or "to write with a pen", what appears to our attention are two things that are related in such a way that our attention, when focused on $A$, tends to include $B$ in the same focalization as well. In fact, the handle is joined to the cup and therefore as long as we look at the cup we also see the handle; and as long as we watch the action of writing we see the pen.

The analysis also clearly explains why the preposition "with" can be used in cases where the other aforesaid relationships (manner, cause, quality, time, opposition etc.) are involved. In all the above-quoted examples the attention, while focusing on something, is also extended to something else (from an activity to the way this activity is performed, from an event to another one that happens at the same time, from the act of opposing someone/something to that someone/something etc.).

Therefore, the preposition does not designate the many relationships that are listed in grammar books and dictionaries, that is, these relationships are not its meanings (which would be too many). The preposition designates a much more general relationship, i. e., $A$ is in such a relationship with $B$ that attention, when focused on $A$, is also led to "embrace" $B$. This very general relationship can include various more specific relationships (company or union, means or instrument, manner, simultaneousness, cause, etc.), which depend on the two related things, but the meaning of the preposition is only the first relationship, not the second ones. Therefore, there is only one meaning for the preposition, in agreement with the fact that there is only one corresponding word.

Similarly to the preposition "with", the two verbs "to have" and "to get" are traditionally believed to be highly polysemous. In fact, dictionaries usually try to capture their meanings by defining each verb with a long list of other verbs (Table 3 ). 
Table 3. The meanings of the verbs "to have" and "to get".

\begin{tabular}{|c|c|}
\hline $\begin{array}{l}\text { to have }=\text { to possess, to own } \\
» »=\text { to keep }\end{array}$ & $\begin{array}{l}\text { John has a new car } \\
\text { he has a knife in his pocket }\end{array}$ \\
\hline$» »=$ to get, to obtain & May I have some tea, please? \\
\hline\|\|$=$ to receive & he had a letter from the bank this morning \\
\hline$» "=$ to dispose of & the rebels have anti-tank missiles \\
\hline$» »=$ to spend & we had a week by the seaside in June \\
\hline$» »=$ to suffer & he had a serious loss \\
\hline$\| »=$ to give birth to & she's having a baby in the autumn \\
\hline to get $=$ to obtain & she got a degree in economics \\
\hline$» »=$ to purchase & he used to get "The Times" \\
\hline$» »=$ to catch & the dog got the ball in his mouth \\
\hline$» »=$ to receive & he got a bicycle for his birthday \\
\hline$» 川=$ to understand & he didn't get the joke \\
\hline$\| »=$ to become & you'll get wet without an umbrella \\
\hline$» »=$ to arrive & how long does it take to get to Liverpool? \\
\hline
\end{tabular}

However, one can easily note that these lists are nothing else but collections of more "specialized" verbs, whose meanings are included in the more general meanings of "to have" and "to get". The meanings of "to have" and "to get" are so general because both these verbs designate the same relationship as the one designated by the preposition "with", i. e., that two distinct things, $A$ and $B$, are related in such a way that our attention, when focusing on $A$, tends to include $B$ in the same focalization as well. The difference with the preposition "with" is that, in the case of these two verbs, as in all verbs, we see the situation from the temporal point of view, which entails focusing our attention continuously or repeatedly on the same situation (according to OL, a meaning of a verbal kind is something that requires a prolonged or repeated attentional focalization to be acknowledged, also see further on). In the case of the verb "to have", the result is something static. For example, "that man has a moustache" means that when we focus our attention on his face we also see a moustache and this remains constant throughout time. On the contrary, in the case of the verb "to get", the result is something dynamic. For example, "to get the pen" means that our hand enters into such a relationship with the pen that, if we look at the hand, we also see the pen (the pen is in the hand), while this relationship did not exist before.

\section{A Grammatical Concept Difficult to Be Defined: "noun"}

A grammatical concept that has proved difficult to be defined is the concept of "noun". OL offers a simple and clear definition of this concept. In order to give this definition, some other general outlines of the theory should be introduced however.

According to OL, linguistic thought is made up of two fundamental kinds of elements:

1) correlators

2) correlata

Correlators are elements whose specific function is to tie the other elements of thought. They are the mental categories designated by adpositions (or the corresponding cases) and conjunctions. Correlata are elements that are "tied" by a correlator: these are nouns, adjectives, pronouns, articles, verbs and adverbs. According to OL, even though the meanings of isolated words (such as "apple") are a kind of thought, actual linguistic thought occurs only when we "tie" or "correlate" more than one meaning to each other, i. e., when we say, for example, "apple and pear", "red apple", etc..

The two correlata that are tied by a correlator are called "first correlatum" and "second correlatum", respectively, according to the temporal order in which attention focuses on them. We call the whole structure that is thus formed correlation or correlational triad and we represent it graphically in the following way:

\begin{tabular}{|c|c|}
\hline \multicolumn{2}{|c|}{ correlator } \\
\hline first correlatum & second correlatum \\
\hline
\end{tabular}

Figure 1. Correlation or correlational triad.

in order to visually suggest the idea that a correlation is a whole where two meanings (the correlata) are tied together by the mental operations that make up the correlator. In the case of the example "pear and apple", we will have this correlation:

\begin{tabular}{|c|c|}
\hline \multicolumn{2}{|c|}{ and } \\
\hline pear & apple \\
\hline
\end{tabular}

Figure 2. An example of correlation.

Besides adpositions (or the corresponding cases) and conjunctions, there is another extremely important correlator. Its structure is the same as for the conjunction "and" (attention focuses on $A$ and $A$ is borne in mind while attention focuses on $B$ ), with the difference that $A$ and $B$ do not remain separate, but are "combined" together. This is due to the fact that the attentional focalization does not stop in the passage from $A$ to $B$ because $A$ and $B$ are in some way complementary. For example, $A$ is an object that can exist on its own and $B$ a possible feature of it (correlation substantiveadjective); or $B$ is what may happen to $A$ in time (correlation subject-verb); or $A$ is a verb and $B$ its object (correlation verb-object ${ }^{4}$ ); etc.. We call this correlator presence keeping and we represent it graphically by means of a horizontal bar:
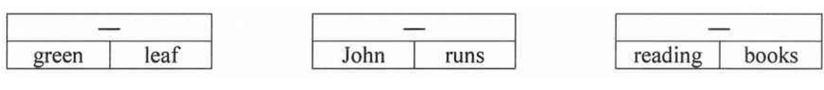

Figure 3. The correlator "presence keeping”.

Since this correlator is, as we can easily understand, the most used of correlators, it is convenient not to express it with a word and to indicate its presence either by simply putting the two words that it correlates one after the other

4 The definition of "verb" according to OL has already been given (p 7). Similarly to generative grammar, OL defines "subject" and "object" syntactically on the basis of their position with respect to the verb in the deep structure of the sentence, where, according to OL, the order of subject, verb and object is always SVO ([57], [58], [59], [60]). 
(when this is possible) or using marks of the words (English has very few marks of this kind, but many languages have several of them: for instance, in the Italian sentence "bottiglia di vino nuova", which means "new bottle of wine", the two "a" that are underlined are marks of the feminine gender, which indicate that the adjective nuova, "new", is related to bottiglia, "bottle", not to vino, "wine").

According to OL, correlation is the minimal and basic unit of linguistic thought. "Minimal unit" means that a linguistic thought is made up of at least one correlational triad (this implies that even in a clause or phrase made up of two monomorphemic words, such as "I run" and "yellow flower", the elements are not two, but three, namely, the two words and the "presence keeping" correlator, which is expressed by putting the two words one after the other ${ }^{5}$ ). "Basic unit" means that linguistic thought is generally a "network" formed by various correlations (correlational network) in which a correlation acts as a correlatum of another correlation. Therefore, the sentence "John reads books and magazines", for instance, has the following structure of thought:

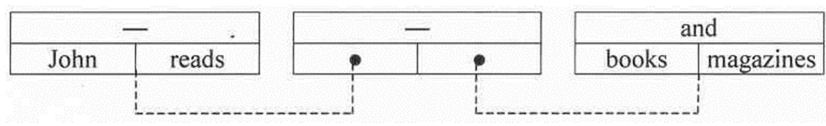

Figure 4. An example of correlational network.

(the dotted line starting from the line that separates the two lower boxes of a correlation and ending with the symbol "•" placed in one of the two lower boxes of another correlation indicates that the first correlation is one of the correlata of the second correlation). This graphic representation (in Ceccato's original form, where the correlational triads are not on the same line), when there are various correlations, resembles a network, hence the expression "correlational network". However, irrespective of the graphic representation, it must be very clear that the structure of linguistic thought is not a simple linear structure where the elements are added one after the other. The elements (that is, the meanings) that make up thought are surely loaded one after the other in working memory, and the previous elements are kept present while the next ones are added. The result, however, is a nonlinear structure, which can be different even when the words are spoken in the same order. For example, the two sentences "empty whisky bottle" and "Scotch whisky bottle" have the same word order (they are made up of a first word, which, albeit different, is in both cases an adjective, plus two identical words in the same order), but the two corresponding correlational networks are different:

\footnotetext{
5 The intuition that in such cases the elements are not two but three can be found in Tesnière ([95]), who based his syntactic theory on the concept of "connection" (connexion). This concept is nevertheless very different from the concept of "correlator", because the "connection" referred to by Tesnière is: a) an implicit link, while OL's concept of "correlator" includes implicit links, links that are indicated by morphological marks, adpositions and conjunctions; b) something very hierarchical, unlike correlator (see further on). Moreover, in Tesnière an analysis in terms of cognitive operations is missing.
}

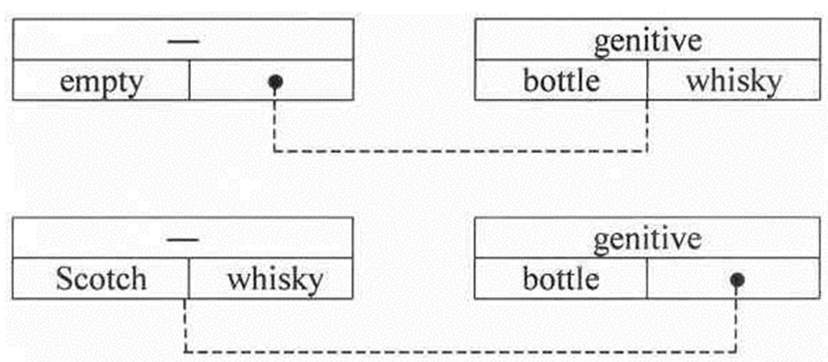

Figure 5. The same word order, but different correlational networks.

The theory of the structure of linguistic thought that has just been outlined (which is Ceccato's own) is called correlational theory of thought. The fact that, despite the (necessarily) linear order of speech, all the elements of a sentence are kept mentally present was also pointed out by a 19th century scholar, Steinthal, even if not in the same cognitive terms as OL (he resorted to the concept of "vibrating representations" [schwingende], see [96], pp. 102112). The concept of difference between the linear order of speech and the non-linear order of thought was also proposed as early as the 1950's by Chomsky ([97]), Tesnière ([95]) and Guillaume ([98]). Ceccato formulated this same concept more or less in the same years, almost surely quite independently. Nevertheless, the conception of the structure of thought by Ceccato is noticeably different from the others, as we will see more clearly further on.

At this point our definition of "noun" can be introduced. As mentioned, the definition of this concept has proved difficult. Nouns are traditionally defined in a semantic way by stating that nouns are the words that indicate "persons, animals, vegetables, unanimated objects". Some grammar books also add "qualities, quantities, ideas", or "places, events" and so on. The "verb" category (which is the main category in contrast with the "noun"; nevertheless, the infinite forms of the verb, i. e., the infinitive, the participle and the gerund, are commonly called "nominal forms") is also generally defined in a semantic way: verbs are said to designate "processes or states". Modern linguistics is perfectly aware that these semantic definitions are unsatisfactory: for example, a word such as "birth" designates a process, but it is a noun, not a verb; words such as "to be born" and "outside" are a verb and an adverb respectively, but they designate an "event" and a "place" respectively, which are among the things that nouns are supposed to designate. Modern linguistics has therefore tried to go beyond these semantic definitions. Often, it has tried to give functional definitions and/or definitions based on the relationships among the parts of speech. The noun, for example, is said to be what occurs with articles and attributive adjectives and can be the head of a nominal phrase. Nevertheless, these definitions are partially not applicable in some languages (for example, Russian and Latin do not have articles), are partially tautological ("nominal phrase") and easily end up being circular (the noun is defined in terms of its relationships with the article and/or adjective, and the latter two are defined, either directly 
or indirectly, in terms of their relationship with the noun). Apart from this, even if a definition of this kind works (i. e., it identifies words that are sensed as nouns), the two following objections are still valid: a) we can say that the definition works exactly because we already sense very well which words in a sentence are nouns; b) the fact that nouns occur with certain other parts of speech does not explain what nouns are, i. e., what their nature is.

The fact is that the real problem is not giving a definition of "noun" that works, i. e., that always identifies which words in a sentence are nouns. The real problem is understanding why we sense very well that in speech there are words that all belong to the same class, which is called the class of "nouns". If we understand this, the definition of "noun" comes automatically.

OL provides a simple and natural solution to this problem. We have to note that:

1) conjunctions, adpositions and the verb in the personal form are never nouns;

2) the verb in the infinitive forms is a noun instead (for example, "reading books");

3) in linguistics, adjectives are commonly considered "nominal forms" as are substantives.

According to OL, the grammar category of "noun" is based on the fundamental distinction between correlators and correlata, i. e., between elements of linguistic thought with the function of linking and elements that are linked by the former. Nouns are the mere correlata, i. e., the words that designate something that has no correlating function, unlike the linguistic elements that designate a correlator or also (see below) a correlator. Nouns are therefore the meanings that, in the graphic representation of the correlation triad we use, are exclusively placed in one of the two lower boxes, unlike the meanings that are placed or are also placed in the upper box (this definition is Ceccato's own). Therefore, according to OL the grammatical category of "noun" can be defined only by using the position the word has in the correlational network (i. e., its function) as a criterion of classification, not by basing ourselves on a semantic criterion. For example, the words "John", "piece", "glass", "doors" and "windows", which are mere correlata in the following correlations are nouns:

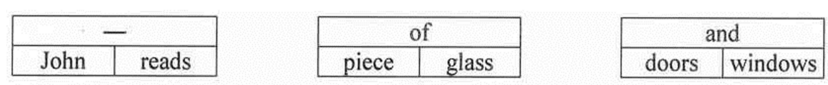

Figure 6. Nouns are mere correlata.

The adjective (as a theme, i. e., apart from the marks of gender, number and case that some languages apply to it) also indicates a mere correlatum, as we can see in this example:

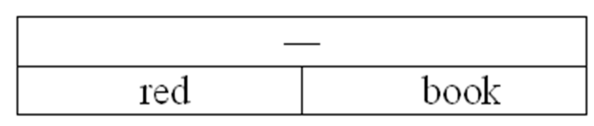

Figure 7. The adjective is a mere correlatum.
Instead, the verb in the personal form is never a "noun", because it does not simply indicate a correlatum (thus it is not a "mere correlatum") but designates that this correlatum (the "bare" meaning of a verb, i. e., the meaning of its theme) is related (as a second correlatum) to what grammar calls a "person" (that is, the agent or the addressee of a linguistic act, or another person/thing [[92], p. 193]) by means of a correlator, presence keeping (therefore, the verb in the personal form indicates both a correlatum and a correlator). For example, the personal form of the verb "to laugh" laugh$s$ indicates that the (verbal) meaning "laugh" is related to a third person singular. Therefore, "laughs" is not a mere correlatum, but designates a whole correlation, i. e. the following:

\begin{tabular}{|l|l|}
\hline \multicolumn{2}{|c|}{-} \\
\hline a third person singular & laugh \\
\hline
\end{tabular}

Figure 8. The verb in the personal form designates a whole correlation.

Instead, the verb in the infinitive mood is a mere correlatum, as in the following examples:

\begin{tabular}{|c|c|c|c|}
\hline \multicolumn{2}{|c|}{-} & \multicolumn{2}{|c|}{ - } \\
\hline to be & strong & reading & books \\
\hline
\end{tabular}

Figure 9. The verb in the infinitive mood is a mere correlatum.

Therefore, in this case the verb is a noun. Thus, the noun/verb distinction does not have a semantic basis, but depends on the function that the meaning at stake has in the correlational network.

Now, it is worthwhile to consider OL's definitions of "noun" and "personal verb" once again, and compare these to each other and to some others.

- noun: as just stated, the concept of "noun" cannot be defined on a semantic basis, but only with a functional criterion, that is, on the basis of the position that a word has in the correlation network: nouns are the mere correlata, that is, the words that designate something that has no correlating function, unlike the linguistic elements that designate a correlator or also a correlator. Nouns include substantives, adjectives (for the definition of these two categories, see below) and the infinitive forms of the verb (the infinitive, the participle, the gerund), the latter which are indeed also called "nominal forms" of the verb.

- verb: what requires a prolonged or repeated attentional focalization to be acknowledged (i. e., is not instantaneously recognizable, as instead happens for the substantive, see below) is a meaning of a verbal kind. This is clear for "processes" (the first of the two things that the verb is traditionally said to be), but is also true for the second, i. e., "states" (it is not possible to say that something, for example, "is still", without looking at it for a certain time). A good example to clearly sense the difference between substantive and meaning of a verbal kind (a dynamic or static one) is imagining a 
ship on the horizon: the ship (i. e., a substantive) is perceived instantaneously, while its moving or being still (i. e., verbs) only with a prolonged observation. Words with a meaning of a verbal kind are, for example, "(he/she/it) breathes", "breathing", "breath", "operation", "discussion", "development", "passage", "arrival" etc.. If a word designates a meaning of a verbal kind and the fact that this is related (as a second correlatum) with a grammatical person (therefore, the word designates both a correlatum and a correlator), it is a verb in a finite mood; if a meaning of a verbal kind is a mere correlatum, it is a nominal form of the verb (for example, "to breathe", "breathing") or a noun having a meaning of a verbal kind (for example, "breath") (we will not discuss what distinguishes the latter two, for example "breathing" and "breath", since this is a minor difference). It is not incorrect to say, as it has been traditionally said, that verbs designate "processes" or "states", but this is not a satisfactory definition of "verb". The traditional definition, instead of really defining verbs, simply lists the two main categories in which verbs can be distinguished (i. e., verbs that designate a process and verbs that designate a state). OL's definition instead is an extralinguistic definition, based on cognitive operations. But the main flaw of the traditional definition is that this definition cannot explain why certain words (for example, "breath"), even if they designate processes, are nouns. The traditional definition cannot explain this fact because it does not clearly distinguish, as OL does, "verb" from "meaning of a verbal kind", and does not grasp the fact that the real opposition is not between "noun" and "verb", but between "meaning of a verbal kind" and "meaning of a substantival kind" (or, simply, "substantive"). OL defines the substantive in the following way.

- substantive: the substantive designates something that is acknowledged in an instantaneous way (i. e., without any need to follow the situation over time, as instead happens for meanings of a verbal kind) and is acknowledged or considered independently from other things (unlike adjectives): for example, all of this applies to words such as "bird" and "flower" (i. e., substantives), but not to words such as "to fly" (i. e., a verb) and "red" (i. e., an adjective). Therefore, OL defines the adjective in the following way.

- adjective: the adjective designates something that is acknowledged in an instantaneous way (therefore, like substantives and unlike meanings of a verbal kind) by separating this something from something else (and therefore, not independently, as the substantive does). For example, the word "red" designates something that is instantaneously acknowledged and that does not exist independently, but is necessarily tied to something else (something red), from which it is isolated by means of the selective ability of attention.

The definitions that have been just proposed, except that of 'noun', are the author's own.

Once we have given our definition of "noun", we can add some considerations about the correlational theory of thought and the concept of "correlation".

1) The fact that OL conceives the structure of linguistic thought as made up of elements having an equal structure, i. e., the correlational triads (where, moreover, the correlator is often the same, i. e., the simple "presence keeping") should not make one think that the concept of correlation is too general or that OL does not accept traditional grammatical concepts such as predication, agreement etc.. On the contrary, OL, too, accepts these concepts (generally speaking, OL accepts all the traditional grammatical concepts-with only marginal modifications - and tries to account for them). Simply, OL maintains that many correlations are based on something common (i. e., the operation of presence keeping, which we believe to be substantially the loading of a meaning in working memory), and the difference amongst these correlations is determined not as much by the correlator as by the correlata. For example, the fact that "John reads" is a "subject-verbal predicate" correlation is determined not by a particular correlator that is different from the correlator of a "substantive-adjective" correlation, for example, but by the two correlata "John" (which is the first correlatum of a verb in the personal form, which, according to OL, makes it a grammatical subject) and "reads" (which is a verb in the personal form, which necessarily involves a subject).

2) It is instead true that the correlational theory of thought differs deeply from the other linguistic theories about sentence structure for at least two reasons.

a) First, according to the correlational theory of thought the fundamental concepts of language are "correlation" and "correlator", while in many other theories the concepts of subject/predicate or nominal phrase/verbal phrase are central. This does not mean that OL rejects the latter. OL simply considers these less central than the concepts of "correlation" and "correlator". According to the correlational theory of thought, what is absolutely necessary in any phrase or sentence are correlators (which are expressed, as mentioned, by putting the words one after the other, or by adpositions, conjunctions, morphological marks, a particular word order - for example, the expression of the genitive by means of the inversion of the order of the two nouns-, or are implicit). Therefore, according to OL, the analysis of a phrase or sentence consists of identifying the correlators and the structure that these form when linking the various correlata. Once we have identified this structure, we can also speak of "subject" and "predicate", "noun phrase" and "verb phrase" etc., but this is less important than identifying the correlational network. Indeed, in some languages a finite verb is not always necessary in order to form a sentence ([92], p. 176). 
Moreover, even in languages, such as English, where this is said to be necessary, linguistic expressions without a subject and a finite verb, such as certain exclamations, titles, labels, captions, are actually found. What instead cannot be missing in any phrase or sentence are correlators, and because of this correlators are considered central by OL. A consequence of this conception is that adpositions (or the corresponding cases) and conjunctions, i. e., parts of speech that have traditionally received less attention than the noun and the verb, become the central parts of speech.

b) Secondly, the correlational theory of thought conceives the structure of linguistic thought as much less hierarchical than many other theories do. For example, the expression "scent of roses" is not described, in our theory, as a noun that governs a prepositional phrase, but as a correlational triad that is made up of a correlator ("of") that ties two correlata (the meanings of the two nouns), which are substantially in a condition of parity, except for the temporal order in which they are focused on by attention and loaded in working memory (therefore, the traditional tree structures or similar representations cannot absolutely be used to represent the structure of thought according to our theory: this subject cannot be addressed in depth here, but is addressed in [55], pp. 4-9, and [56], pp. 18-19).

3) The correlational theory of thought easily explains why a certain sequence of words in a given language is grammatical or not, which is a central problem in generative grammar. This subject requires a great deal of space to be addressed and is therefore completely out of the scope of a brief article such as this. Here, we can only say that the correlational theory of thought uses the distinction between correlators and correlata, and the fact that two correlata are necessarily tied by an (explicit or implicit) correlator to decide if a string of words is grammatical or not (nevertheless, the syntactic rules of the language should also be considered).

\section{The Other Main Features of OL in Brief}

We have introduced a few analyses of mental categories only, and we will not add others, because these are sufficient to present our theory. Here we will instead illustrate the other main features of the theory very briefly. The ideas introduced in this section are all the author's own, except point 3.

1) OL provides, in a very natural manner, a new solution to a central question in the philosophy of language and psycholinguistics, i. e., whether language is an evolutionary product of increased human intelligence over time and social factors, or if language exists because humans possess an innate ability, an access to what has been called a "universal grammar"-the first view is well represented by the mentalistic theories of Piaget, the empiricism of Carnap etc.; the second point of view can be said to have begun with Chomsky ([99]). Indeed, OL presupposes that it is only the ability of carrying out the EOMC that is innate, while, on the contrary, the ability of making up mental categories by means of these operations, and of building the structure of thought by means of the mental categories, is acquired and culturally transferred, from generation to generation. According to OL, which mental categories are built with the (few) EOMC (which are innate) and which structures of thought are built with these mental categories (in other words, grammar) does not depend on an innate device, but on the usefulness of these mental categories and structures of thought in satisfying the communicative needs of human beings (needs that are more or less the same for all humans). This assumption implies that said mental categories and types of structures of thought are widely common (consequently, translation from any language into any other language is always substantially possible), but also that, since there is no innate universal grammar, there can be differences across languages. This is exactly what happens, as we all know. For example, making a distinction between the things that exist (or are considered) independently, i. e., in an isolated manner (as mentioned, according to OL these are the meanings of substantives) and what happens to these things over time (the meanings of verbs) is too much useful and important to be missing in a language: indeed, having substantives and verbs is a linguistic universal ([91], p. 277 It. ed.; [92], p. 117; [100], p. 14). On the contrary, for example, making a distinction, by means of two different demonstrative adjectives, between when something is far from both the speaker and the addressee and when something is far from the speaker but close to the addressee, is not that essential, so that there can be languages that do this (such as Latin, with the ille/iste pair) and others that do not (such as English, which uses the demonstrative adjective "that" in both cases).

The thesis of OL on the innate or acquired origin of language is simple and natural. In fact, the existence of a small innate component only (i. e., operations within cognitive functions) is a completely plausible hypothesis and one that avoids the difficulties that derive from hypothesizing the existence of an innate "deep" universal grammar, namely a) the little intrinsic plausibility of this hypothesis, and b) the need to reduce the differences found across the grammars of the various languages to a unique universal grammar. On the other hand, resorting to the cultural factor alone is probably insufficient to explain the analogies, which far exceed the differences, across languages, and the huge difference between human thought/language and animal thought/communication.

2) OL, with its description of linguistic thought in terms of 
operations of attention and other cognitive functions, makes it clearer what the essence of human/thought language is, and allows us to better account for the huge difference between human thought/language and animal thought/communication (which is another fundamental issue in psycholinguistics). In brief, according to OL human thought/language is based on two fundamental processes. The first process is a fragmentation of the experience, a fragmentation that is allowed by the selective ability of attention. This fragmentation leads to the formation of a large number of meanings (for example, the perception of an object with its color, say a green leaf or a red apple, is a unitary experience, but human attentional ability allows humans to isolate the shapes of the leaf and the apple from the color green and the color red, thus creating the four meanings "leaf", "green", "apple" and "red"; the same happens in countless other situations, such as the isolation of the action of "flying" from the object "bird", the meaning of the adjective "hard" from the object "stone", etc.). The second process is a recombination of these many single different meanings that is carried out thanks to the correlators and that leads to the formation of the correlational networks, i. e., the sentences. In this way humans, by means of a number of words that is limited (even if rather big: the words that designate the aforesaid many meanings that have been created, i. e., the lexicon of a language), can produce an unlimited number of utterances, that is, they can describe any experience. For instance, with the words of the aforesaid example, they can describe, besides a green leaf and a red apple, a green apple and a red leaf too. According to OL, the huge difference between human thought/language and animal thought/communication is due, among other things, to the very fact that: a) animals, even if some probably have perceptual abilities (hence, are able to have experiences) that are not very different from ours, probably have an attentional ability that is much less sophisticated than the human one, and does not allow the aforesaid process of fragmentation; b) animals are not probably provided with the ability to produce the mental categories of relationship, i. e., the correlators (hence, the correlational network), a task that definitely requires a big capacity of working memory. Therefore, OL ascribes the difference between human language and animal communication, among other factors that have been highlighted by previous literature (which OL does not reject at all), not to a substantial difference between the cognitive abilities of humans and those of animals, but to a different development of the same abilities, thereby recognizing that there is no fracture between human beings and animals, but only a different degree of evolution.

3) OL is an approach to the study of language, hence something strictly theoretical. Nevertheless, OL could also have at least one practical spin-off. In fact, the correlational theory of thought has led to conceive a device for the implementation of an innovative machine translation program, which might allow us to achieve a better translation quality than that of the programs available today (the references for the history and the state-of-the-art of machine translation are: [101], [102], [103], [104], [105], [106], [107]). This device is described in detail in [55]. This device was conceived by Ceccato and his collaborators in this project ([46]; [108]).

\section{A Comparison Between OL and Other Approaches}

Since an in-depth comparison between OL and other approaches is well beyond the scope of a brief article such as this, here we will just mention the main approaches that can be considered.

One can easily understand that OL is substantially incompatible with generative grammar. First of all, because in generative grammar syntax is central, while according to OL what is central is semantics and syntax is nothing else but an aspect of semantics. The other major difference with generative linguistics is the fact that, as mentioned in the previous section, OL conceives no innate ability or device specific for language. OL maintains that the only (even if fundamental) innate component of language are cognitive functions (amongst which attention plays a key role), which therefore are not at all specific for language itself. As for the rest, language is essentially a cultural product, and the fundamental factor that determines the meanings present in it is the usefulness of these meanings in satisfying the communicative will of humans. Therefore, OL's conception is radically different from that of language as an innate and universal ability of humans, which is typical of the generative tradition. In a certain sense, one can say that the two conceptions are opposite: according to generative linguistics, language originated from something, which is specific (i. e., the appearance, in an evolutionary sense, of a specific device), while according to OL language originated for something (i. e., a purpose, that of satisfying the communicative will of humans), based on preexisting nonspecific functions. Besides the fact that both theories, like others, are mentalistic, the only analogy can perhaps be the fact that OL, too, conceives a structure of linguistic thought, i. e., a deep level, which: a) is always different, as regards a certain aspect, i. e., its non-linear structure, from the surface structure, which is necessarily linear, and b) can be different in some cases, for example from the superficial SVO order, as mentioned in note 4 .

OL is also incompatible with logical-formal approaches originating from the work by Russell, Frege, Wittgenstein and Tarski, such as truth-conditional semantics, Montague grammar, etc.

OL is also substantially different from the structuralist approach, where grammatical elements are often accounted for in terms of relationships of opposition to each other, or 
sometimes considered to substantially lack a meaning and take various meanings according to the context ${ }^{6}$.

OL also substantially differs from distributional approaches, which account for linguistic elements in terms of relationships of occurrence with each other.

On the contrary, OL has something in common with cognitive linguistics (that is, the theories proposed by authors such as Lakoff ([65]), Langacker ([109], [110], [111]), Talmy ([112], [113]), and others), such as the conception that language is not based on an ad hoc device but on pre-existing cognitive functions, and the recurrence of the concepts of "construction" and "operations", so that OL could even be considered a theory within cognitive linguistics, even if the two approaches originated in a completely independent way from each other. Nevertheless, there also are important differences. Cognitive linguistics, indeed, extensively deals with the lexical meanings (on the contrary, OL deals mainly with the grammatical meanings), and seems to focus more on the influence that the cognitive operations have on the whole sentence or the choice of a word inside the sentence, while OL provides an analysis in terms of "atomic" components of the meaning of the single grammatical elements.

The idea that there is a close relationship between attention and meaning was already put forward about a century ago by Valéry ([114]) and Vygotskij ([115]), but just as a hint (that is, systematic attempts at analyzing meaning in attentional terms were not performed, as instead Ceccato and the SOI did). On the contrary, systematic attempts have been performed in the last past decades by various authors, such as Oakley, Carstersen, Talmy, and Lampert. It is important to note that these scholars came to put forward the hypothesis that attention plays a key role in the construction of meaning in a completely independent manner from the SOI. This basic presupposition is clearly present in Oakley's work ([116], [117]). Indeed, even if Oakley bases his semantic analyses on the "Mental Spaces and Blending Theory" originally developed by Fauconnier and Turner, he conceives the operations relevant to such spaces as attentional phenomena. However, Oakley too, as the others cognitive linguists, generally analyzes the whole sentence or text, not the single linguistic elements (as instead OL does), because he considers the context as decisive for the construction of meaning, and as prevailing over the basic meaning of each single word. Undoubted analogies with OL's approach can be found in the semantic analyses of locative expressions by Carstensen ([11], [12], [13]), who resorts to the concept of attentional operations performed by the subject (such as "shift", "zooming", see the concept of movement of attentional focus included in the EOMC (section 3.2) and the author's analyses of locative terms in [56], [57], [58], [59], [60]). Talmy ([118], [119]) has investigated the role played by attention in meaning selection and construction by means of a specific research program (Linguistic Attention). This

6 A comparison with logical-formal and structuralist approaches can be found in [61], pp 191-192. program has been also maintained by Lampert ([120], [121], [122], [123]).

The developmental psychologist Mandler ([124], [125], [126], [127]) has developed a theory according to which meanings are abstractions that derive from perception by means of spatial attention.

The relationship between attention, space (and, more in general, perception) and meaning is also stressed by another scholar, Bolles ([128], [129], [130]).

The relationship between attention and meaning has been also investigated and proved by experimental researches (even if not related to the aforesaid specific research programs), such as, for example, those by Logan (which concerned spatial concepts, [131]), Taube-Schiff and Segalowitz (which showed that grammatical elements act as an attention-directing mechanism, [132]), and Tomlin (which concerned the relationships between the direction of attention and the choice of the grammatical subject of the sentence, [133]). The importance of some form of attention for some categories of words has been also partially acknowledged by linguists who have not developed theoretical frameworks of analysis of meaning in attentional terms, such as, for example, Diessel (according to whom demonstratives function to coordinate the interlocutors' joint focus of attention, [134], [135]). For an in-depth survey of the status of the research on the relationships between attention and meaning, see [136].

Something similar to the distinction between correlators and correlata can be found in the classification of the "grammatical concepts" made by Sapir, who divided them into two main categories depending on whether they concerned the "material content" or the "relationship", and also stated that two subcategories of these two categories are essential to any form of language ([137]). In Sapir this distinction seems to refer more to the level of language than that of thought, is not expressed in cognitive terms, and is less central. Nevertheless, Ceccato and Zonta ([50]) explicitly acknowledge that Sapir's approach to the classification of the parts of speech is "the closest" to OL's.

As a general consideration, while some similarities between OL and the other approaches can be found, they are very limited and sporadic: if OL is compared with the other theories as a whole, OL proves to be something deeply different.

\section{Conclusion}

This article aims to introduce a new theory that deals mainly with the problem of the meaning of the fundamental grammatical elements of language (not single languages). We have introduced the general outlines of the theory only, in order to give a general idea in the space of an article. The theory is based on the fundamental presupposition that the meaning of grammatical elements has to be searched for not, or not only, at the level of the particular objective situations where these linguistic elements are used, but at the top level of abstractness, i. e. at the level of the cognitive operations 
performed by the subject, amongst which those of attention play a key role. The theory, albeit systematic and, from a certain point of view, complete, is nevertheless a first attempt in this direction and as such may contain mistakes or may need to be widened or modified. Nevertheless, this theory seems to take us, in a simple and natural way, towards a unitary solution of the problem as a whole. This leads me to suppose that this is at least the right direction to follow in order to solve this problem in the philosophy of language.

\section{References}

[1] Cooper, G.S., 1968. A Semantic Analysis of English Locative Prepositions. Bolt, Beranek \& Newman report 1587.

[2] Bennett, D.C., 1975. Spatial and Temporal Uses of English Prepositions: An Essay in Stratificational Semantics. Longman, London.

[3] Herskovits, A., 1981. On the Spatial Use of Prepositions in English. Linguisticae Investigationes 2, 303-327.

[4] Herskovits, A., 1986. Language and Spatial Cognition. Cambridge University Press, New York.

[5] Jackendoff, R., 1983. Semantics and Cognition. MIT Press, Cambridge, Massachusetts.

[6] Jackendoff, R., 1990. Semantic Structures. MIT Press, Cambridge, Massachusetts.

[7] Lakoff, G., 1987. Women, Fire, and Dangerous Things. The University of Chicago Press, Chicago.

[8] Di Tomaso, V., 1996. Un'analisi semantica di alcune preposizioni italiane. Studi Italiani di Linguistica Teorica e Applicata, 25 (2), 257-290.

[9] Tyler, A., Evans, V., 2003. The Semantics of English Prepositions: Spatial Scenes, Embodied Meaning and Cognition. CUP, Cambridge.

[10] Carstensen, K.-U., 1995. "Semantic and Conceptual Aspects of Local Expressions: Critical Remarks on the 'State of the Art'”. In M. Bierwisch and P. Bosch (Eds.), Semantic and Conceptual Knowledge, Workshop-Proceedings of the SFB 340 "Sprachtheoretische Grundlagen für die Computerlinguistik", Report Nr. 71, 117-126.

[11] Carstensen, K.-U., 2002. Location and distance in language: An attention-based approach. Paper presented at the 3rd Annual Language \& Space Workshop 'Resolution and Granularity in Language and Space'. ZIF, Univ. Bielefeld. 8./9. 7. 2002.

[12] Carstensen, K.-U., 2007. Spatio-temporal ontologies and attention. Spatial Cognition and Computation 7(1), 13-32.

[13] Carstensen, K.-U., 2015. A Cognitivist Attentional Semantics of Locative Prepositions. In: Marchetti G., Benedetti G. and Alharbi A. (Eds.), Attention and Meaning. The Attentional Basis of Meaning. Nova Science Publishers, Hauppauge, New York, pp 93-132.

[14] Glasersfeld, E. von, 1989. Linguaggio e comunicazione nel costruttivismo radicale. Cooperativa Libraria Universitaria del Politecnico, Milano.
[15] Glasersfeld, E. von, 1998. Il costruttivismo radicale. Società Stampa Sportiva, Roma.

[16] Benedetti, G., 2009. The meaning of the basic elements of language in terms of cognitive operations: Operational Semantics. Advanced Studies in Biology, Vol. 1, 2009, no. 5$8,255-305$.

[17] Benedetti, G., 2010. A semantics of the fundamental structural elements of language, based on cognitive functions: Operational Semantics. In: Salvati G., Rabuano V. (Eds.), Cognitive Psychology Perspectives. Nova Science Publishers, Hauppauge, New York, pp. 1-61.

[18] Benedetti, G., 2011. An enigma in language - The meaning of the fundamental linguistic elements. A possible explanation in terms of cognitive functions: Operational Semantics. Nova Science Publishers, Hauppauge, New York.

[19] Agud, A., 1980. Historia y teoría de los casos. Gredos, Madrid.

[20] Hjelmslev, L., 1935, 1937. La catégorie des cas: première partie and deuxieme partie. Acta Jutlandica VII, IX $(1,2)$.

[21] Serbat, G., 1981. Cas et fonctions. PUF, Paris.

[22] Blake, B. J., 1994. Case. Cambridge University Press, Cambridge.

[23] Marmo, C., 2004. Semiotica e linguaggio nella scolastica. Parigi, Bologna, Erfurt (1270-1330). La semiotica dei Modisti. Istituto Storico Italiano per il Medioevo, Roma.

[24] Arnauld, A., Lancelot, C., 1660. Grammaire générale et raisonnée, Paris [It. ed. by Simone, R., 1969. Grammatica e Logica di Port-Royal, Ubaldini Editore, Rome].

[25] Jakobson, R., 1936. Beitrag zur allgemeinen Kasuslehre: Gesamtbedeutungen der russuschen Kasus. Travaux du Cercle Linguistique de Prague 6, 240-288.

[26] Groot, A. W. de, 1939. Les oppositions dans les systémes de la syntaxe et des cas. In: Mélanges de Linguistique offerts à Charles Bally. George et Cie, Genève, pp. 107-127.

[27] Groot, A. W. de, 1956. Classification of the uses of a case illustrated on the genitive in Latin, Lingua 6, 8-66.

[28] Kuryłowicz, J., 1949. Le problème du classement des cas, again printed in: Esquisses linguistiques I, 1973, (2d. ed.), München, Fink, 131-150.

[29] Kuryłowicz, J., 1964. The inflectional categories of IndoEuropean. Winter, Heidelberg.

[30] Rubio, L., 1966. Introducción a la sintaxis estructural del latin, vol. I. Ariel, Barcelona.

[31] Benveniste, E., 1962. Pour l'analyse des fonctions casuelles: le génitif latin. Lingua 11, 10-18.

[32] Fillmore, Ch. J., 1968. The case for case. In: Bach, E., Harms, R. T. (Eds.), Universals in Linguistic Theory. Holt, Rinehart and Winston, New York, pp. 1-88.

[33] Chomsky, N., 1981. Lectures on government and binding. Foris, Dordrecht.

[34] Anderson, J. M., 1977. On Case Grammar: Prolegomena to a Theory of Grammatical Relations. Croom Helm, London.

[35] Anderson, J. M., 1997. A notional theory of syntactic categories. Cambridge University Press, Cambridge. 
[36] Anderson, J. M., 2006. Modern Grammar of cases: a retrospective. Oxford University Press, Oxford.

[37] Perret, J., 1965. La signification du génitif adnominal. R.E.L. 43, 466-482.

[38] Shumaker, N. W., 1975. The Semantics of the English's Genitive. American Speech. A Quarterly of Linguistic Usage, 50, pp. $70-86$.

[39] Durieux, F., 1990. The Meanings of the Specifying Genitive in English. A Cognitive Analysis. Antwerp.

[40] Rosenbach, A., 2002. Genitive Variation in English. Conceptual Factors in Synchronic and Diachronic Studies, pp. 28-29. Mouton de Gruyter, Berlin/New York.

[41] Vikner, C., Jensen, P. A., 2002. A Semantic Analysis of The English Genitive. Interaction of Lexical and Formal Semantics. Studia Linguistica 56 (2), 191-226.

[42] Kreyer, R., 2003. Genitive and of-construction in modern written English: Processability and human involvement. International Journal of Corpus Linguistics 8, 169-207.

[43] Ceccato, S., 1964. Un tecnico fra i filosofi vol. I, Come filosofare. Marsilio Editori, Padova.

[44] Ceccato, S., 1966. Un tecnico fra i filosofi vol. II, Come non filosofare. Marsilio Editori, Padova.

[45] Ceccato, S., 1968. Cibernetica per tutti, 1. Feltrinelli, Milano (edited by Barosso G.)

[46] Ceccato, S. (ed), 1969. Corso di linguistica operativa. Longanesi, Milano.

[47] Ceccato, S., 1970. Cibernetica per tutti, 2. Feltrinelli, Milano (edited by Giuliani M.V., Zonta B.)

[48] Ceccato, S., 1972. La mente vista da un cibernetico. ERI, Torino.

[49] Ceccato, S., 1974. La terza cibernetica. Feltrinelli, Milano (edited by Zonta B.).

[50] Ceccato, S., Zonta B., 1980. Linguaggio consapevolezza pensiero. Feltrinelli, Milano.

[51] Benedetti, G., 1999. La categoria di "spazio", and Tavole sinottiche delle analisi di categorie mentali tratte dalle opere di S. Ceccato. In: Accame F., Glasersfeld E. von, Somenzi V., Beltrame R., Panetta M., Menga C.E., Benedetti G., Studi in memoria di Silvio Ceccato. Società Stampa Sportiva, Roma.

[52] Benedetti, G., 2004. Semantica operativa. www.mindconsciousness-language.com

[53] Benedetti, G., 2005a. A presentation of Operational Methodology. www.mind-consciousness-language.com.

[54] Benedetti, G., 2005b. Basic mental operations which make up mental categories. www.mind-consciousness-language.com.

[55] Benedetti, G., 2005c. A device in order to improve the quality of machine translation, based on the correlational theory of thought. www.mind-consciousness-language.com.

[56] Benedetti, G., 2006. Operational Noology as a new methodology for the study of thought and language: theoretical aspects and possible practical applications. Cognitive Processing 7, 217-243.
[57] Benedetti, G., 2008. A semantics "outside language": Operational Semantics. A new semantic theory, based on the nature and structure of thought. www.mind-consciousnesslanguage.com

[58] Benedetti, G., 2009. The meaning of the basic elements of language in terms of cognitive operations: Operational Semantics. Advanced Studies in Biology, Vol. 1, 2009, no. 5$8,255-305$.

[59] Benedetti, G., 2010. A semantics of the fundamental structural elements of language, based on cognitive functions: Operational Semantics. In: Salvati G., Rabuano V. (Eds.), Cognitive Psychology Perspectives. Nova Science Publishers, Hauppauge, New York, pp. 1-61.

[60] Benedetti, G., 2011. An enigma in language - The meaning of the fundamental linguistic elements. A possible explanation in terms of cognitive functions: Operational Semantics. Nova Science Publishers, Hauppauge, New York.

[61] Marchetti, G., 2006. A presentation of attentional semantics. Cognitive Processing 7, 163-194.

[62] Marchetti, G., 2010. Consciousness, Attention and Meaning. Nova Science Publishers, Hauppauge, New York.

[63] Marchetti, G., 2015. Attentional Semantics: An Overview. In: Marchetti G., Benedetti G. and Alharbi A. (Eds.), Attention and Meaning. The Attentional Basis of Meaning. Nova Science Publishers, Hauppauge, New York, pp 93-132.

[64] Barsalou, L. W., 1999. Perceptual symbol systems. Behavioral and Brain Sciences 22, 577-660.

[65] Lakoff, G., 1987. Women, Fire, and Dangerous Things. The University of Chicago Press, Chicago.

[66] Rosch, E., 1973. Natural Categories. Cognitive Psychology, 4, 328-350.

[67] Rosch, E., 1978. Principles of categorization. In: Rosch, E., Lloyd Hillsdale, B. (Eds), Cognition and Categorization. Lawrence Erlbaum Ass, N.J..

[68] James, W., 1890. The principles of psychology. Holt, New York (Reprint 1983: Harvard University Press, Cambridge, MA).

[69] Baddeley, A. D., Hitch, G. J., 1974. Working memory. In: Bower, G.A. (Ed.), Recent advances in learning and motivation, vol. 8. Academic Press, New York, pp. 47-90.

[70] Baddeley, A. D., 2000. The episodic buffer: a new component of working memory? Trends in Cognitive Sciences 4, 417-423.

[71] Cowan, N., 2001. The magical number 4 in short-term memory: A reconsideration of mental storage capacity. Behavioral and Brain Sciences 24, 87-185.

[72] Cowan, N., 2005. Working memory capacity. Psychology Press, New York, NY.

[73] Oberauer, K., Süß, H-M., Schulze, R., Wilhelm, O., Wittmann, W. W., 2000. Working memory capacity - facets of a cognitive ability construct. Personality and Individual Differences 29, 1017-1045.

[74] Oberauer, K., 2002. Access to information in working memory: exploring the focus of attention. Journal of Experimental Psychology: Learning, Memory, and Cognition 28, 411-421. 
[75] Jonides, J., 1983. Further toward a model of the mind's eye's movement. Bulletin of the Psychonomic Society 21, 247-250.

[76] La Berge, D., 1983. The spatial extent of attention to letters and words. Journal of Experimental Psychology: Human Perception and Performance 9, 371-379.

[77] La Berge, D., 1995. Attentional processing. The brain's art of mindfulness. Harvard University Press, Cambridge, MA.

[78] Pashler, H. E., 1998. The psychology of attention. MIT Press, Cambridge, MA.

[79] Posner, M. I., 1980. Orienting of attention. Quarterly Journal of Experimental Psychology 32, 3-25.

[80] Posner, M. I., 1994. Attention in cognitive neuroscience: an overview. In: Gazzaniga, M. (Ed.), The cognitive neurosciences. MIT Press, Cambridge, MA.

[81] Posner, M. I., Cohen, Y., 1984. Components of performance. In: Bouma, H., Bowhuis, D. (Eds.) Attention and performance. Erlbaum, Hillsdale, NJ.

[82] Braga-Illa, F. (Ed.), 1997. Livelli di rappresentazione. Percorsi tra il naturale e l'artificiale. Quattro Venti, Urbino.

[83] Braga-Illa, F. (Ed.), 2006. A proposito di rappresentazioni. Alla ricerca del senso perduto. Pendragon, Bologna.

[84] Denis, M., 1989. Image et cognition. Presses Universitaires de France, Paris.

[85] Miller, G. A., 1956. The magical number seven, plus or minus two: some limits on our capacity for processing information. Psychological Review 63, 81-97.

[86] Benjafield, J.G., 1997. Cognition. Prentice-Hall International, Englewood Cliffs.

[87] Reed, S. K., 1992. Cognition. Theory and applications. Wadsworth, Belmont, CA.

[88] Rizzi, L., 1988. "Il sintagma preposizionale”. In: Grande grammatica italiana di consultazione, vol. I, ed. L. Renzi (Il Mulino, Bologna, pp. 507-531.

[89] Zelinsky-Wibbelt, C. (ed), 1993. The semantics of prepositions: from mental processing to natural language processing. Mouton de Gruyter, Berlin, New York.

[90] Di Tomaso, V., 1996. Un'analisi semantica di alcune preposizioni italiane. Studi Italiani di Linguistica Teorica e Applicata, 25 (2), 257-290.

[91] Yule, G., 1996. The study of language. Cambridge University Press, Cambridge.

[92] Graffi, G., Scalise, S., 2002. Le lingue e il linguaggio. Il Mulino, Bologna.

[93] Saint-Dizier, P. (ed), 2006. Syntax and semantics of prepositions. Springer, Dordrecht.

[94] Tobin, Y., 2008. A monosemic view of polysemic prepositions. In: Dennis, K., Adler S. (Eds.) Adpositions: Pragmatic, semantic and syntactic perspectives. John Benjamins Publishing Company, Amsterdam, Philadelphia.

[95] Tesnière, L., 1959. Eléments de syntaxe structurale. Klincksieck, Paris.
[96] Steinthal, H., 1860. Assimilation und Attraktion, psychologish beleuchtet, in "Zeitschrift für Völkerpsychologie und Sprachwissenschaft”, I, pp. 93-179.

[97] Chomsky, N., 1957. Syntactic Structures. Mouton, The Hague.

[98] Guillaume, G., 1971-2010 [based on 1938-1960 lectures, author's note]. Leçons de linguistique (20 volumes). Presses de l'Université Laval, Quebec.

[99] Chomsky, N., 1959. A review of B. F. Skinner's Verbal Behavior. Language 35 (1), 26-58.

[100] Frigerio, A., 2011. Filosofia del linguaggio. Apogeo, Milano.

[101] Hutchins, W. J., 1986. Machine translation: past, present, future. Ellis Horwood Series in Computers and their Applications, Chichester.

[102] Hutchins, W. J., Somers H. L., 1992. An introduction to machine translation. Academic Press, London.

[103] Hutchins, W. J., 1999. Retrospect and prospect in computerbased translation. Machine Translation Summit VII, 13th-17th September 1999, Kent Ridge Digital Labs, Singapore. Proceedings of MT Summit VII "MT in the great translation era". Asia-Pacific Association for Machine Translation, Tokyo, 30-34.

[104] Hutchins, W. J., 2001a. Towards a new vision for MT. Introductory speech at the "MT Summit VIII" conference. Santiago de Compostela, Galicia, Spain.

[105] Hutchins, W. J., 2001b. Machine translation and human translation: in competition or in complementation? International Journal of Translation 13 (1-2), 5-20. Also in: Blekhman MS (Ed.) Machine translation theory \& practice. Bahri Publications, New Delhi.

[106] Hutchins, W. J., 2002. Machine translation today and tomorrow. In: Willée, G., Schröder, B., Schmitz, H-C. (eds) Computerlinguistik: was geht, was kommt? Festschrift für Winfried Lenders. Gardez! Verlag, Sankt Augustin, 159-162

[107] Hutchins, W. J., 2003. Has machine translation improved? Proceedings of the Ninth Machine Translation Summit. AMTA, East Stroudsburg, PA, 181-188.

[108] Glasersfeld, E. von, Pisani P. P., 1970. The multistore parser for hierarchical syntactic structures. Communications of the ACM 13 (2), 74-82.

[109] Langacker, R. W., 1987. Foundations of Cognitive Grammar, vol. 1: Theoretical Prerequisites. Stanford University Press, Stanford.

[110] Langacker, R. W., 1991. Foundations of Cognitive Grammar, vol. 2: Descriptive Application. Stanford University Press, Stanford.

[111] Langacker, R. W., 2008. Cognitive Grammar: A Basic Introduction. Oxford University Press, Oxford.

[112] Talmy, L., 2000a. Toward a Cognitive Semantics. Volume I: Concept Structuring System. The MIT Press. Cambridge, Mass.

[113] Talmy, L., 2000b. Toward a Cognitive Semantics. Volume II: Typology and Process in Concept Structuring. The MIT Press. Cambridge, Mass.

[114] Valéry, P., 1973. Cahiers. Ed. by J. Robinson-Valéry. Gallimard. Paris. 
[115] Vygotskij, L.S., 1935. Problemy psichičeskogo razvitija rebënka. (Italian translation, 1984: Lo sviluppo psichico del bambino. Editori Riuniti. Roma).

[116] Oakley, T., 2004. Elements of Attention: A new Approach to meaning Construction in the Human Sciences. Partly Carissimo, available from: http://www.mind-consciousnesslanguage.com/articles\%20oakley $1 . \mathrm{htm}$

[117] Oakley, T., 2009. From Attention to Meaning. Explorations in Semiotics, Linguistics, and Rhetoric. Peter Lang. Bern.

[118] Talmy, L., 2007. Attention phenomena. In: Dirk Geeraerts and Hubert Cuyckens (Eds.), Handbook of Cognitive Linguistics. Oxford University Press.

[119] Talmy, L., 2008. Aspects of attention in language. In: P. Robinson and E. C. Nick (Eds.), Handbook of Cognitive Linguistics and Second Language Acquisition. Routledge. New York \& London.

[120] Lampert, M., 2009. Attention and Recombinance: A Cognitive-Semantic Investigation into Morphological Compositionality in English. Lang. Frankfurt am Main.

[121] Lampert, M., 2011. Attentional Profiles of Parenthetical Constructions: Some Thoughts on a Cognitive-Semantic Analysis of Written Language. International Journal of Cognitive Linguisitcs, Vol. 2 (1), 81-106.

[122] Lampert, M., 2013. Cognitive Semantics goes multimodal: Looking at quot(ativ)es in face-to-face-settings. International Journal of Cognitive Linguisitcs, Vol. 4 (2).

[123] Lampert, M., 2013. How Attention Determines Meaning: A Cognitive-Semantic Study of the Steady-State Causatives Remain, Stay, Continue, Keep, Still, On. In: Marchetti G., Benedetti G. and Alharbi A. (Eds.), Attention and Meaning. The Attentional Basis of Meaning. Nova Science Publishers, Hauppauge, New York, pp 93-132.

[124] Mandler, J. M., 2010. The spatial foundations of the conceptual system. Language and Cognition, 2, 21-44.

[125] Mandler, J. M., 2011. A leaner nativist solution to the origin of concepts. Behavioral and Brain Sciences, 34, 138-139.

[126] Mandler, J. M., 2012. On the spatial foundations of the conceptual system and its enrichment. Cognitive Science, 36, 421-451.

[127] Mandler, J. M., 2015. Attention as the Origin of Meaning Formation. In: Marchetti G., Benedetti G. and Alharbi A. (Eds.), Attention and Meaning. The Attentional Basis of Meaning. Nova Science Publishers, Hauppauge, New York, pp 93-132.

[128] Bolles, E. B., 2011. Babel's Dawn: A Natural History of the Origins of Speech. Counterpoint Press. Berkeley.

[129] Bolles, E. B., 2015a. The Evolution of a Hierarchy of Attention. In: Marchetti G., Benedetti G. and Alharbi A. (Eds.), Attention and Meaning. The Attentional Basis of Meaning. Nova Science Publishers, Hauppauge, New York, pp 93-132.

[130] Bolles, E. B., 2015b. Attention-based syntax. www.mindconsciousness-language.com

[131] Logan, G. D., 1995. Linguistic and conceptual control of visual spatial attention. Cognitive Psychology, 28, 103-174.

[132] Taube-Schiff, M. \& Segalowitz, N., 2005. Linguistic Attention Control: Attention Shifting Governed by Grammaticized Elements of Language. Journal of Experimental Psychology: Learning, Memory, and Cognition, 31, 508-519.

[133] Tomlin, R. S., 1997. Mapping Conceptual Representations into Linguistic Representations: The Role of Attention in Grammar. In: J. Nuytsand and E. Pederson (Eds.), Language and Conceptualizations. Cambridge University Press, Cambridge, 162-189.

[134] Diessel, H., 2006. Demonstratives, joint attention, and the emergence of grammar. Cognitive Linguistics, 17, 463-489.

[135] Diessel, H., 2014. Demonstratives, frames of reference, and semantic universals of space. Language and Linguistics Compass, $8 / 3,116-132$

[136] Marchetti G., Benedetti G. and Alharbi A. (Eds.), 2015. Attention and Meaning. The Attentional Basis of Meaning. Nova Science Publishers, Hauppauge, New York, pp 93-132.

[137] Sapir, E., 1921. Language. Harcourt, Brace \& World, New York. 